\title{
1. Field Performance Assessment of a 2 Hydrokinetic Turbine
}

3

\author{
Robert J. Cavagnaro ${ }^{a^{*}}$, Brian Polagye ${ }^{a}$ \\ ${ }^{a}$ Northwest National Marine Renewable Energy Center, University of Washington, \\ Mechanical Engineering, Stevens Way, Box 352600, Seattle WA, 98195
}

\section{Keywords}

Tidal turbine, hydrokinetic, power take-off, dynamometry, component efficiency

\begin{tabular}{|ll}
\hline Nomenclature and Abbreviations \\
$A$ & rotor projected area \\
$A D V$ & acoustic Doppler velocimeter \\
$c$ & blade chord length \\
$C_{P}$ & coefficient of performance \\
$D$ & turbine diameter \\
$H$ & turbine span/height \\
$\tilde{I}$ & generator current, dynamometry \\
$I$ & generator current \\
$I M U$ & inertial measurement unit \\
$I_{U}$ & turbulence intensity \\
$K_{V}$ & generator voltage constant \\
$N$ & number of blades \\
$N_{B}$ & gearbox ratio \\
$P_{e}$ & electrical power \\
$P_{k}$ & kinetic power \\
PTO & power take-off \\
$r$ & turbine radius \\
$R$ & resistive load \\
$t$ & blade thickness \\
$U_{\infty}$ & undisturbed upstream water velocity \\
$\tilde{V}$ & generator voltage, dynamometry \\
$*$ Corresponding author.
\end{tabular}

Email addresses: rcav@uw.edu (R. J. Cavagnaro), bpolagye@uw.edu (B. Polagye)

Phone numbers: +1-917-838-7625 (R. J. Cavagnaro), +1-206-543-7544 (B. Polagye) 


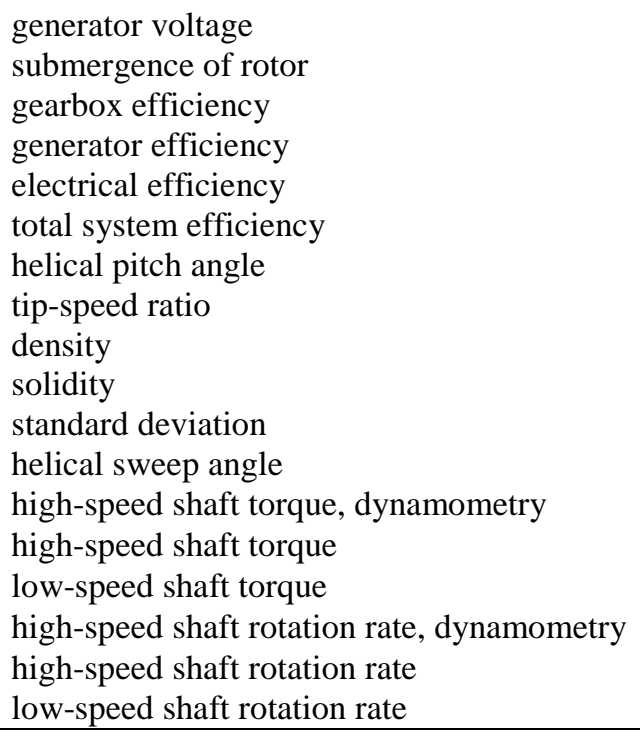

\section{Introduction}

Development of hydrokinetic turbines used for electricity generation involves advancing systems through technology readiness and performance levels to commercialization [1,2]. Field testing of scaled prototypes is a critical phase of development following laboratory experimentation and addresses two potential limitations under laboratory conditions. First, a turbine's hydrodynamic performance and thrust can be augmented in confined flow (such as a recirculating laboratory flume or tow tank) due to increased mass flux through the turbine and accelerated flow around the turbine, resulting in a higher pressure drop across the rotor [3]. Second, below a critical Reynolds number, where the lift and drag coefficients of hydrofoils depend on current velocity, rotor performance also depends on current velocity $[4,5,6]$.

Because hydrofoils in a cross-flow turbine (rotation axis perpendicular to direction of flow) undergo dynamic stall as a consequence of large changes in the angle of attack, a critical Reynolds number cannot be accurately determined from static foil data [7]. In a laboratory setting, it can be difficult to achieve Reynolds independence due to limitations on maximum velocity in experimental facilities and the aforementioned consequences of flow confinement as model size increases.

In addition, laboratory characterization often does not involve a complete power take-off (PTO). The PTO components convert the mechanical power extracted from flow into electrical power. These components can critically affect the dynamics and performance of hydrokinetic systems [8]. Therefore, prototype tests including a PTO (e.g., gearbox, generator, electrical load) are necessary to quantify overall system performance. Total system efficiency $\left(\eta_{S}\right)$ is defined as the fraction of available kinetic power, $\left(P_{k}\right)$ converted to electrical power $\left(P_{e}\right)$,

$$
\eta_{s}=\frac{P_{e}}{P_{k}} .
$$

24 A turbine's mechanical efficiency, referred to as the coefficient of performance $\left(C_{P}\right)$, is given by

$$
C_{P}=\frac{P_{m}}{P_{k}}=\frac{\tau_{\mathrm{lss}} \omega_{l s s}}{1 / 2 \rho A U_{\infty}^{3}}(2)
$$


where $\tau_{l s s}$ is the rotor (low-speed shaft) hydrodynamic torque, $\omega_{l s s}$ is the rotor rotation rate, together defining mechanical power $\left(P_{m}\right), \rho$ is the density of water, $A$ is the rotor projected area, and $U_{\infty}$ is the undisturbed upstream water velocity. The projected, area of a cross-flow turbine is defined as

$$
A=2 r H(3)
$$

where $H$ the height of the rotor. The coefficient of performance under a given oppositional load can be compared to the tip-speed ratio $(\lambda)$,

$$
\lambda=\frac{\omega_{l s s} r}{U_{\infty}}(4)
$$

in which $r$ is the turbine radius. In unconfined flow above a critical Reynolds number, the combination of $C_{P}$ and $\lambda$ result in a performance curve unique to the turbine geometry.

If $\tau_{l s s}, \omega_{l s s}$, and $U_{\infty}$ are measured, total system efficiency can be determined with further knowledge of individual PTO component efficiencies, such as those of a generator $\left(\eta_{G}\right)$, gearbox $\left(\eta_{B}\right)$, and additional mechanical and electrical losses $\left(\eta_{L}\right)$,

$$
\eta_{s}=C_{P} \eta_{G} \eta_{B} \eta_{L}
$$

PTO component manufacturers often provide a single value for efficiency at implied peak or rated operating conditions, but the actual efficiency may depend on a number of factors, such as output torque in comparison to rated torque [9].

This paper presents the system performance of a field-scale hydrokinetic turbine (nominally, $1 \mathrm{~kW}$ rated mechanical power). Performance is characterized utilizing multiple methods, including one that reduces the number of direct measurements required. The efficiency of the PTO generator and gearbox are explored through laboratory dynamometry. Performance characteristics determined at the scale studied in this work may be compared to those of a $1 / 4$-scale model with similar geometry tested in a recirculating flume to demonstrate differences related to scale [4,10]. Additionally, sufficient detail of the turbine design, test conditions, and performance is provided such that the results may be used to validate numerical studies. In Section 2, the turbine is described and its instrumentation and field testing methodology are detailed. Additionally, the method of laboratory dynamometry used to characterize PTO components is developed. Results from field testing and dynamometry are presented in Section 3 . The implications of these results are discussed in Section 4. Overall, this study provides a detailed picture of the performance of a field-scale hydrokinetic turbine in open-water conditions and recommendations to improve the efficacy of field testing.

\section{Methods}

\subsection{Turbine and instrumentation description}

The field-scale turbine (Fig. 1) is a helical, cross-flow design with circular endplates for blade attachment and a central shaft for support and PTO integration. Its four blades are mounted at the halfchord point with $0^{\circ}$ preset-pitch with respect to the tangent of the circumference of the turbine at the endplate. Each blade consists of a straight profile helically swept around $90^{\circ}(\varphi)$ of the circumference with a helical pitch angle $(\theta)$ of $60^{\circ}$. Consequently, the four blades' chords $(c)$ provide complete coverage of the rotor circumference. The turbine is supported with a steel radial ball bearing at the top of the rotor shaft, and a combination radial needle and thrust bearing (Misumi) at the bottom of the shaft. The turbine is enclosed in a four-post support cage that includes mounting points. Turbine solidity $(\sigma)$ is 0.3 , defined as,

$$
\sigma=\frac{N c}{\pi D}(6)
$$


where $N$ is the number of blades and $D$ is the diameter of the turbine, and represents the fraction of the rotor's total swept area $(\pi D H)$ occupied by blade and ranges from 0 to 1 [11]. This definition is preferred over a version commonly used for wind turbines as in [12], which compares blade area to rotor projected area. As swept area and projected area are equal for an axial-flow turbine, defining solidity as (6) represents an equivalent quantity for a cross-flow turbine. The solidity of the presently studied turbine is relatively high and has the effect of increasing starting ability with more consistent torque at the expense of peak $C_{P}$ and rotation rate [11]. Dimensions for the turbine are reported in Table 1.
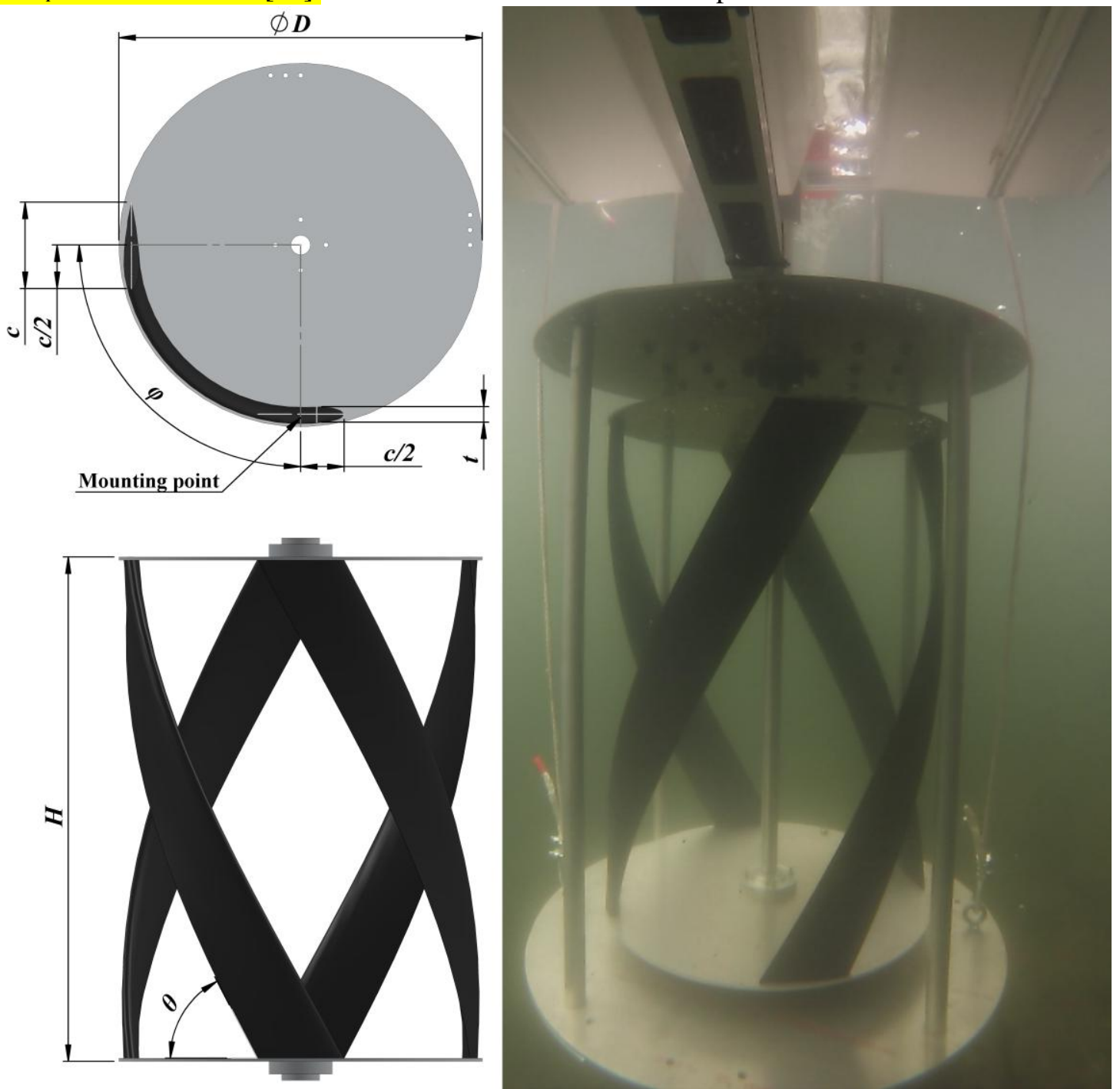

Fig. 1. Field-scale hydrokinetic turbine design and photograph of submerged turbine.

Table 1: Turbine parameters and dimensions

\begin{tabular}{|c|l|}
\hline Parameter & \multicolumn{1}{c|}{ Value } \\
\hline Blade profile & NACA 0018 \\
\hline$N$ & 4 \\
\hline Blade pitch at mount point & $0^{\circ}$ \\
\hline$D$ & $0.72 \mathrm{~m}$ \\
\hline$H$ & $1.01 \mathrm{~m}$ \\
\hline$H / D$ & 1.40 \\
\hline$\theta$ & $60^{\circ}$ \\
\hline$\varphi$ & $90^{\circ}$ \\
\hline
\end{tabular}




\begin{tabular}{|l|l|}
\hline$c$ & $0.17 \mathrm{~m}$ \\
\hline$t$ & $0.03 \mathrm{~m}$ \\
\hline$\sigma$ & 0.30 \\
\hline
\end{tabular}

The PTO consists of a planetary gearbox (Thomson UltraTRUE) and a permanent magnet generator (WindBlue DC-540). The gearbox ratio $\left(N_{B}\right)$ is 10 and the relation between generator (high-speed shaft) rotation rate $\left(\omega_{h s s}\right)$ and torque $\left(\tau_{\text {hss }}\right)$ and low-speed shaft (rotor) values is given as,

$$
\begin{gathered}
\omega_{h s s}=N_{B} \omega_{l s s}(7) \\
\tau_{h s s}=\frac{\tau_{l s s}}{N_{B}} \eta_{B} \eta_{L}(8)
\end{gathered}
$$

where $\eta_{B} \eta_{L}$ is the balance of system efficiency, primarily associated with torque losses through the gearbox. Three-phase, AC power produced by the generator is transformed through a full-wave diode rectifier to yield DC power. This is dissipated through a 10-position adjustable resistive bank with loads $(R)$ ranging from $0.3 \Omega$ to $1000 \Omega$, providing discrete torque control of the turbine. Angular position of the drive shaft is measured with a submersible magnetic encoder (RLS RM22) and thru-shaft optical encoder (Futek TRS605). Turbine rotational rate, $\omega_{l s s}$, is calculated by a first-order backwards difference of the angular position. During field tests, instantaneous generator voltage $(V)$ and current $(I)$ are measured across the resistive load by transducers (LEM LV 25-P and LA 55-P, respectively). Mechanical torque produced by the turbine is measured by a rotary torque sensor (Futek TRS605). Torque losses associated with bearing friction are unquantified. Consequently, the output of the torque sensor is considered to be a direct measurement of $\tau_{l s s}$. All turbine performance data is acquired at a sampling rate of $100 \mathrm{~Hz}$ through a USB DAQ (National Instruments 6210) connected to a laptop computer. Inflow velocity is acquired at $32 \mathrm{~Hz}$ near the centerline of the turbine with an acoustic Doppler velocimeter (ADV, Nortek Vector) mounted two turbine diameters upstream of the axis of rotation.

\subsection{Turbine testing method}

In the field, relative velocity can be induced by placing a turbine in a moving flow (analogous to a recirculating flume at laboratory scale) or by translating a turbine through quiescent flow (analogous to a tow tank at laboratory scale). The latter method was employed in these tests, towing the turbine through an open portion of a still lake (Lake Washington, WA, USA) with a depth greater than $5 \mathrm{~m}$. Testing occurred on calm days with negligible wind waves. A dimensioned schematic of the test arrangement is depicted in Fig. 2. The system was mounted to the transom of a small unpowered catamaran-hulled vessel (Livingston LV12) and positioned such that the top of the rotor sat at a depth per diameter ratio $(z / D)$ of roughly 0.7 below the surface of the water. The drive shaft extended above the surface and was coupled to the torque sensor, gearbox, and generator. These were supported by a rigid mounting to the vessel to reduce vertical thrust loads on the shaft. The torque sensor was protected in a water-resistant enclosure, including a double O-ring seal. The generator was connected to the load bank aboard the vessel. The test vessel was tethered to a powered vessel approximately $100 \mathrm{~m}$ upstream, reducing the impact of the powered vessel wake on turbine performance. The vessel was piloted at three approximately constant speeds of $1.0 \mathrm{~m} / \mathrm{s}, 1.6 \mathrm{~m} / \mathrm{s}$, and $2.1 \mathrm{~m} / \mathrm{s}$ corresponding to blade-chord Reynolds numbers $\left(U_{\infty}\right.$ velocity reference) of 1.5-3.3×105. Each of the 10 resistive load settings was maintained for approximately $45 \mathrm{~s}$ after a steady rotation rate was reached (e.g., after transient from adjusting load settings). Care was taken to avoid contamination by interaction of the towed vessel with large wakes from other vessels on the lake; test runs in the presence of such wakes were aborted. Vessel pitch was monitored with a mechanical level and maintained near-neutral by shifting ballast between the bow and stern under different test 
conditions. Pitch angle was also recorded throughout testing by the inertial measurement unit (IMU) on the ADV.

The ADV measured the upstream velocity in a small sample volume $\left(1.8 \times 10^{-6}\right) \mathrm{m}^{3}$ at a distance of $0.15 \mathrm{~m}$ below the probe head. The velocity at this point was assumed to be representative of the inflow across the rotor swept area. This is reasonable, given that the turbine was being towed through a quiescent fluid, such that inflow velocity varies in time, but was homogeneous in space. Given the similarity between the upstream tow vessel speed and average inflow velocity, angular and axial induction appear to be minimal at this proximity (2D) to the turbine. A square-profile bracket ( $0.09 \mathrm{~m}$ wide) was used to mount the ADV head. Turbulence generated by the bracket is unlikely to significantly affect turbine performance for two reasons. First, the characteristic dimension of the bracket is much smaller than the rotor diameter and smaller than the blade chord, such that the generated turbulence would be unlikely to affect performance [13]. Second, the turbine was 17-times the profile dimension downstream of the ADV, such that the turbulent eddies shed by the ADV would be substantially mixed with the free stream.

Velocity measurements were de-spiked by a 3-D phase-space algorithm [14]. To characterize turbulent inflow conditions, measurement samples of $300 \mathrm{~s}$ were selected from extended tows at each of the nominal speeds used for performance characterization tests. Linear trends were subtracted and then each time-series was split into windows of $32 \mathrm{~s}$, a Hamming filter applied, and each window overlapped by $50 \%$ [15]. Spectra for each window were averaged to yield a single turbulence spectrum for each speed with narrow confidence intervals [16]. A standard bulk metric for describing turbulence [17], turbulence intensity $\left(I_{U}\right)$ was also calculated as the ratio of the standard deviation of the inflow speed $\left(\sigma_{U}\right)$ to its mean $\left(\left\langle U_{\infty}\right)\right.$, 


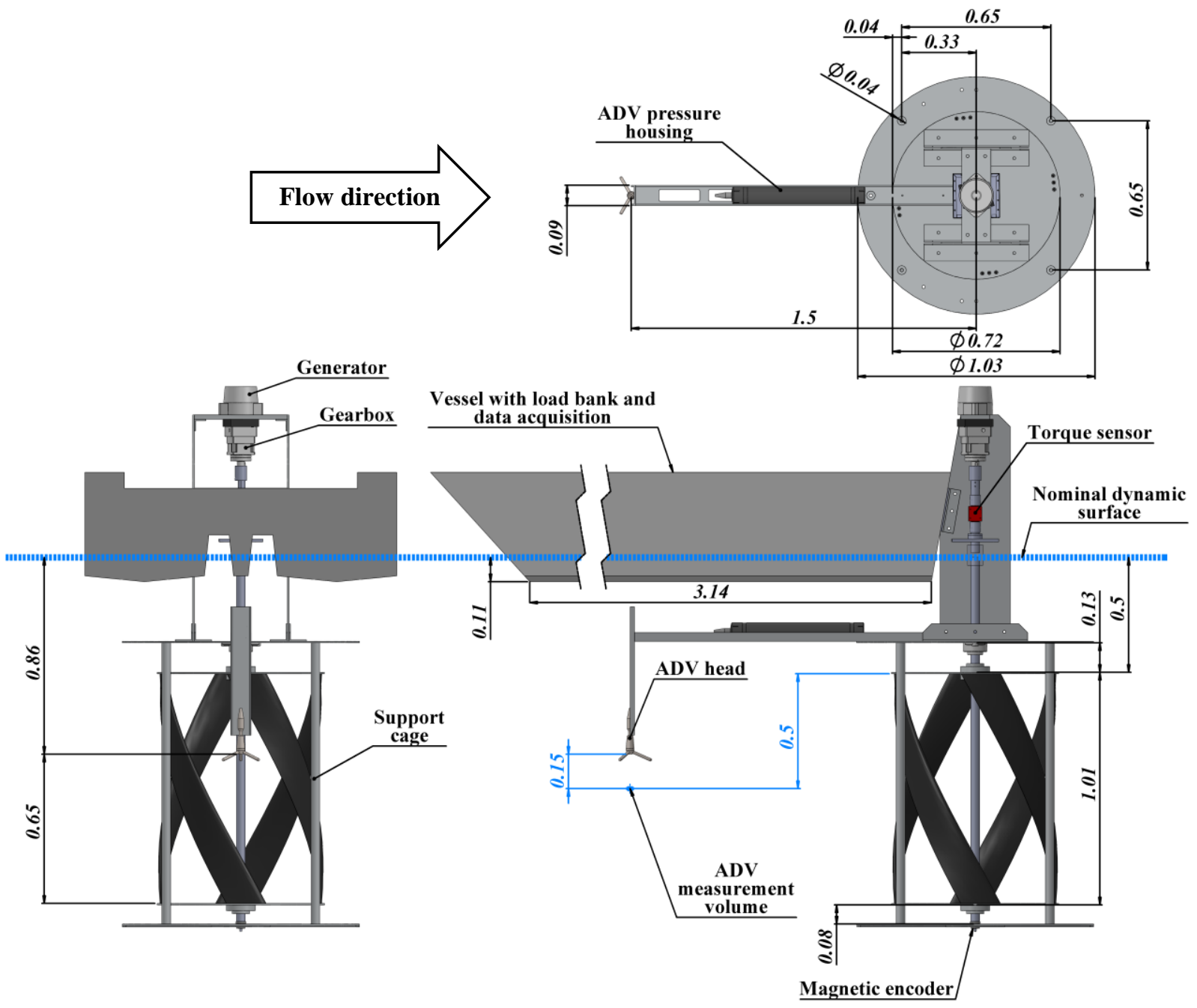

Fig. 2. Field-scale tow testing schematic. Dimensions are in $\mathrm{m}$.

\subsection{PTO dynamometry}

A laboratory dynamometer (Fig. 3) was used to characterize $\eta_{G}$, using a second generator identical to the one coupled to the turbine as the mechanical power input to the PTO. This generator was operated as a variable speed motor controlled with a variable frequency drive (VFD) (Yaskawa V1000). This motor was mounted to a reaction torque sensor (Futek TFF425) measuring input torque, $\tilde{\tau}_{h s s}$, and was flexibly coupled to the generator. Note that here, and for the remainder of the paper, any quantity with a tilde denotes a laboratory dynamometry measurement. An optical encoder (Encoder Products 260) on the dynamometer shaft recorded angular position (used to determine shaft rotation rate, $\widetilde{\omega}_{\text {hss }}$ ). The generator under test was connected to the same 10-position resistive load bank used in the field testing to record dynamometry voltage and current, $\tilde{V}$ and $\tilde{I}$, respectively. The motor was commanded to run over a range of speeds from 10 to $1000 \mathrm{rpm}$ at each of the resistive loads, including specific tests that matched average generator-side rotation rate and resistive load from the field trials. Commanding the same constant rotation rate under the same $R$ electromechanically emulates the turbine at steady state in the laboratory, including the torque produced. Generator efficiency was calculated from these measurements as, 


$$
\eta_{G}\left(R, \omega_{h s s}\right)=\frac{\tilde{V I}}{\tilde{\tau}_{h s s} \tilde{\omega}_{h s s}} .
$$

The electromechanically emulated turbine system in the dynamometry experiment differs from the actual turbine system of field testing in its lack of a gearbox and lack of frictional losses associated with the turbine bearings. Therefore, the difference in electrical power output between tests with the same mechanical input (rotation rate and applied load) represents the losses associated with the gearbox and bearings in the field test. If frictional losses in the dynamometer are neglected, $\eta_{B} \eta_{L}$ can be expressed as,

$$
\eta_{B} \eta_{L}\left(R, \omega_{h s s}\right)=\frac{V I}{\tilde{V I}}
$$
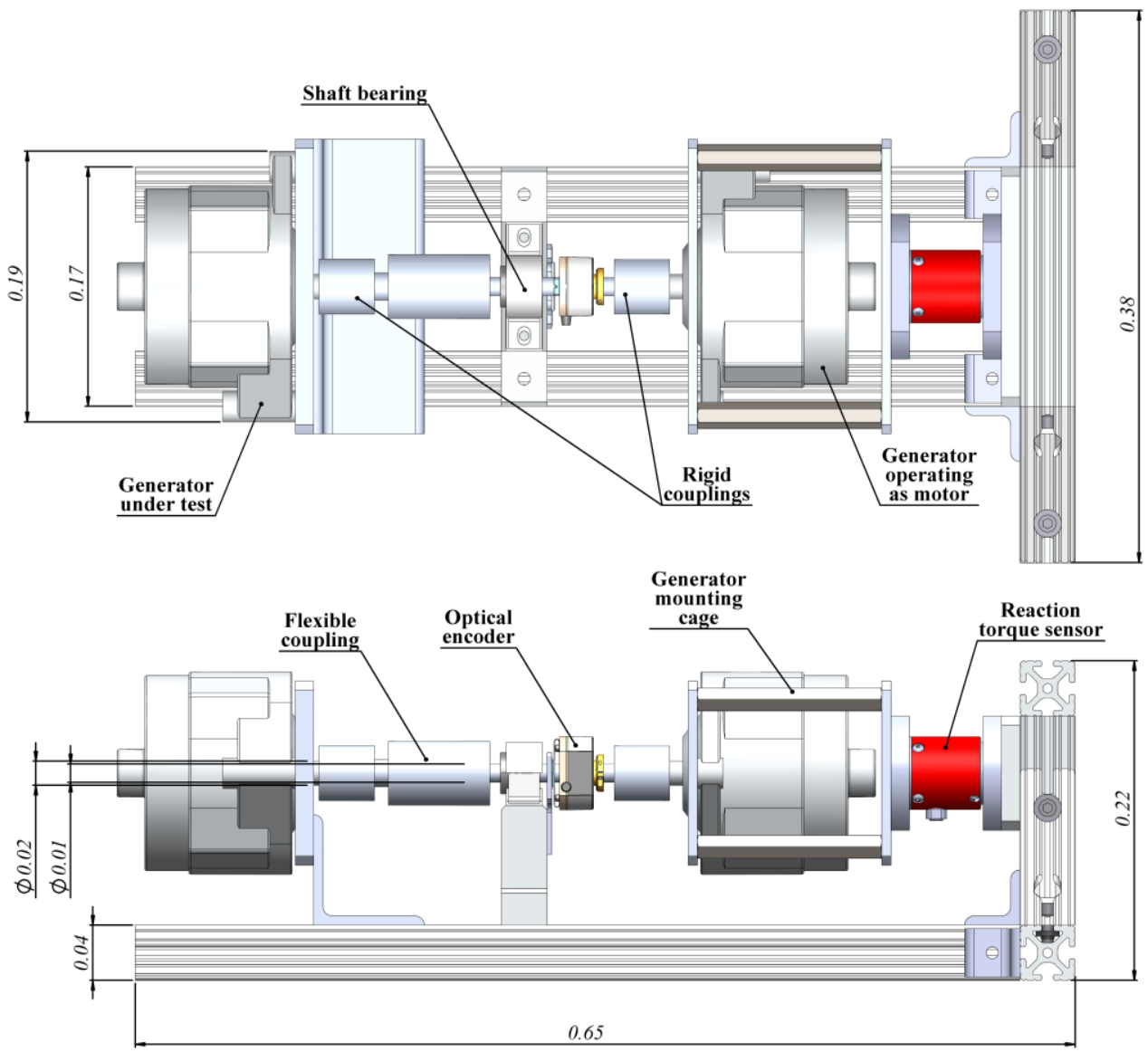

Fig. 3. Generator characterization dynamometer. Dimensions are in $\mathrm{m}$.

\subsection{Mechanical efficiency calculation}

Non-dimensional mechanical efficiency $\left(C_{P}\right.$ as a function of $\left.\lambda\right)$ was evaluated through two independent tests: utilizing direct torque and rotation rate measurement from field measurements to solve for $C_{P}$ in (2) directly, and deriving $C_{P}$ by applying corrections for PTO efficiency to the total system efficiency as in (5). Field and laboratory tests are equated by setting the dynamometry generator speed to match those obtained in the field under the same $R$,

$$
\tilde{\omega}_{h s s}=\omega_{h s s}
$$




$$
\tilde{\tau}_{\mathrm{hss}}=\frac{\tau_{h s s}}{\eta_{B} \eta_{L}}=\frac{\omega_{h s s} K_{V}^{2}}{\eta_{B} \eta_{L} R}(13)
$$

where $K_{V}$ is the generator's voltage constant $(\mathrm{V} / \mathrm{rad} / \mathrm{s})$, which does not change between field and laboratory testing. The relation between mechanical efficiency, resistive load, and rotation rate is apparent by substituting (1) in (5),

$$
C_{P}\left(R, \omega_{h s s}\right)=\frac{P_{e}}{P_{k}} \frac{1}{\eta_{G} \eta_{B} \eta_{L}}(14)
$$

and then (2), (10), and (11) in (14),

$$
C_{P}\left(R, \omega_{h s s}\right)=\frac{V I}{1 / 2 \rho A U_{\infty}^{3}} \frac{\tilde{\tau}_{h s s} \tilde{\omega}_{h s s}}{\tilde{V I}} \frac{\tilde{V I}}{V I}=\frac{\tilde{\tau}_{h s s} \tilde{\omega}_{h s s}}{1 / 2 \rho A U_{\infty}^{3}} .
$$

Consequently, the mechanical efficiency is the ratio between the mechanical power needed to emulate the turbine at steady state and the kinetic power of the resource. While the final form of (15) is functionally similar to (2), it is important to note that the numerator here corresponds to an emulated, rather than actual, turbine that performs independently of the PTO components. As is discussed in Section 4, this relation is critical to enabling $C_{P}$ to be inferred from field data with a limited number of measurements $\left(\omega_{l s s}, U_{\infty}\right.$, and $\left.R\right)$.

\section{Results}

\subsection{Inflow characteristics}

During tests, inflow speeds measured by the ADV averaged $1.0 \mathrm{~m} / \mathrm{s}, 1.6 \mathrm{~m} / \mathrm{s}$, and $2.1 \mathrm{~m} / \mathrm{s}$, in general agreement with target tow vessel speeds of $1 \mathrm{~m} / \mathrm{s}, 1.5 \mathrm{~m} / \mathrm{s}$, and $2 \mathrm{~m} / \mathrm{s}$ with deviation between the two caused by discrete throttle settings for the powered vessel. In Fig. 4, turbulence spectra in the tow-induced inflow are compared to those measured while the vessel was freely drifting in the lake and with a comparable mean speed at a representative tidal energy site (Admiralty Inlet, WA, USA) [17]. During testing, turbulence spectra exhibited slight variation with tow speed. Low frequency peaks (2-5 seconds) were present while towing or drifting as a consequence of interactions with small wakes from other vessels, and oscillations in tow vessel velocity. As evidenced by studies of wave-current interaction, low frequency disturbances do not significantly affect mean values $[18,19]$. The peak observed at $5.5 \mathrm{~Hz}$ for the $1.6 \mathrm{~m} / \mathrm{s}$ and $2.1 \mathrm{~m} / \mathrm{s}$ spectra was likely the result of motion contamination from mechanical vibration transmitted through the cantilevered instrument mounting arm, consistent with increasing energy at higher inflow velocities. Beam correlation averaged $80 \%$, indicating limited interference from surface effects such as bubbles. Speed measured by the ADV while freely drifting averaged $0.07 \mathrm{~m} / \mathrm{s}$. The average pitch angle during characterization tests, as measured by the ADV, ranged from $2.2^{\circ}$ to $4.0^{\circ}$. Inflow turbulence intensity was $5.6 \%$ at $1.0 \mathrm{~m} / \mathrm{s}$ and $1.6 \mathrm{~m} / \mathrm{s}$, and $4.1 \%$ at $2.1 \mathrm{~m} / \mathrm{s}$. This level of turbulence is ascribed to the wakes, waves, tow vessel propeller wash, and tow speed variation responsible for the spectral peaks. Turbulence intensity was lower than during similar mean flow in Admiralty Inlet (7.5\% for the reported sample). The spectra for the tows were flatter than those from Admiralty Inlet, lacking lower frequency, higher energy variation associated with tidal forcing and large anisotropic eddies; these features are not present in the lake. 


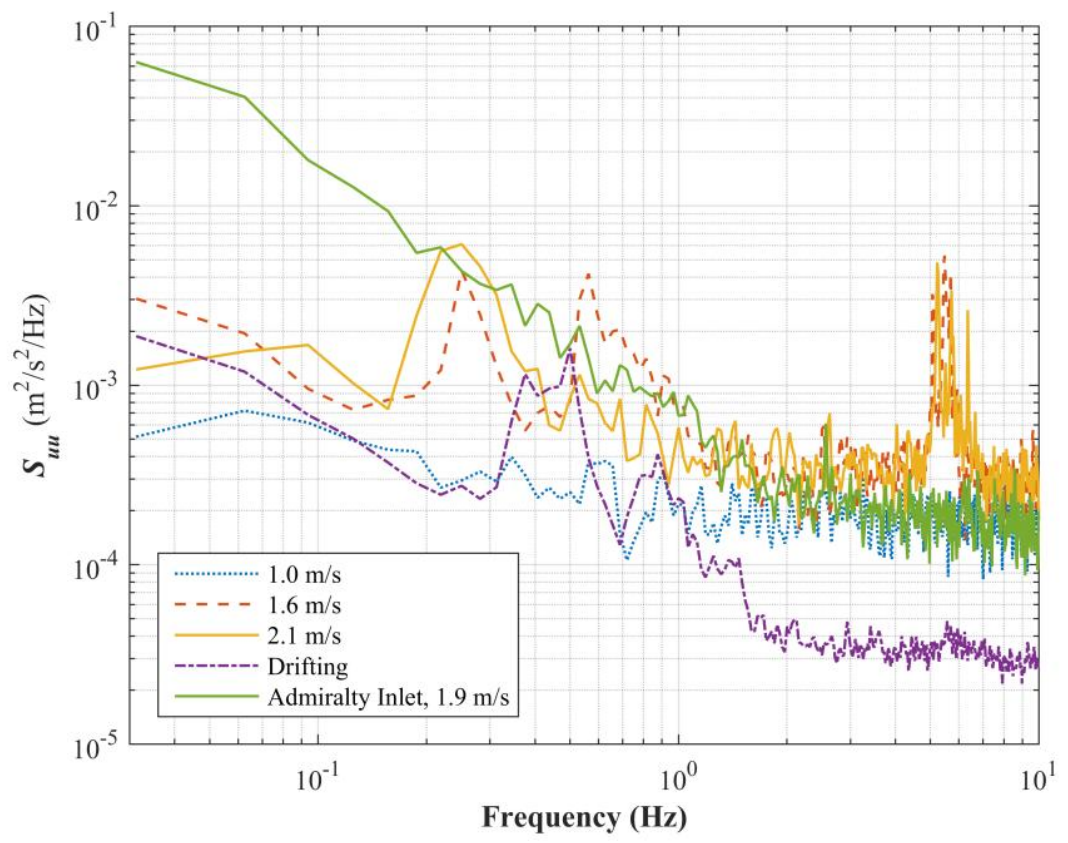

Fig. 4. Turbulent kinetic energy spectra of field test inflow compared to drifting and a representative tidal energy site.

\subsection{Turbine performance}

System efficiency, $\eta_{S}$, (Fig. 5a) varied between tests at the three nominal inflow speeds, resulting in three distinct curves with a maximum efficiency of 0.09 at $1.0 \mathrm{~m} / \mathrm{s}$ and $1.6 \mathrm{~m} / \mathrm{s}$, dropping to 0.07 at 2.1 $\mathrm{m} / \mathrm{s}$. The $\eta_{s}-\lambda$ curve also contracts as inflow velocity increases, with peak efficiency occurring at higher $\lambda$. Generator and balance of system efficiencies were estimated for each of these test cases using laboratory dynamometry and (10 - 11), as shown in Fig. 5b. The PTO component performance varied non-linearly with $\lambda$. PTO efficiency ranged from a minimum of 0.02 to a maximum of 0.67 . The PTO efficiency correction from (15) was applied to the field results for each test case, yielding a derived $C_{P^{-}} \lambda$ curve. In Fig. 5c, these points are compared to those obtained by measuring torque and rotation rate directly. In all cases, cubic polynomials were fit to the experimental data to more clearly demonstrate trends. Peak measured performance, implied peaks from the polynomial fit, and quality of the fit are summarized in Table 2. Through direct measurement and correction for pointwise PTO efficiency, the $C_{P^{-}}$ $\lambda$ curves are in general agreement between tow conditions and are significantly less dependent on inflow velocity than the $\eta_{s}-\lambda$ curves. Much of the remaining variability in the magnitude of $C_{P}$ falls within the bounds of random and systematic experimental uncertainty, shown as error bars in the plot (calculation in an appendix). However, both direct and derived curves for the $1.0 \mathrm{~m} / \mathrm{s}$ case show lower performance than the faster speeds. The case with largest variation and uncertainty in the observed trends of performance is the $1.6 \mathrm{~m} / \mathrm{s}$ derived curve, which exhibits peak performance at a $9 \%$ lower $\lambda$ than the direct measurement at this speed. In general, the uncertainty is higher for the derived curves due to the uncertainty in the dynamometer torque measurement calibration (discussion in appendix) and may be systematically biased towards lower $C_{P}$, though percent difference between measured and derived values is demonstrably low. Reduced performance at the slowest tow speed may be ascribed to either higher relative frictional losses at low rotation rates or exceeding the critical Reynolds number between 1.0 and $1.6 \mathrm{~m} / \mathrm{s}$ tow speeds. 
(a)

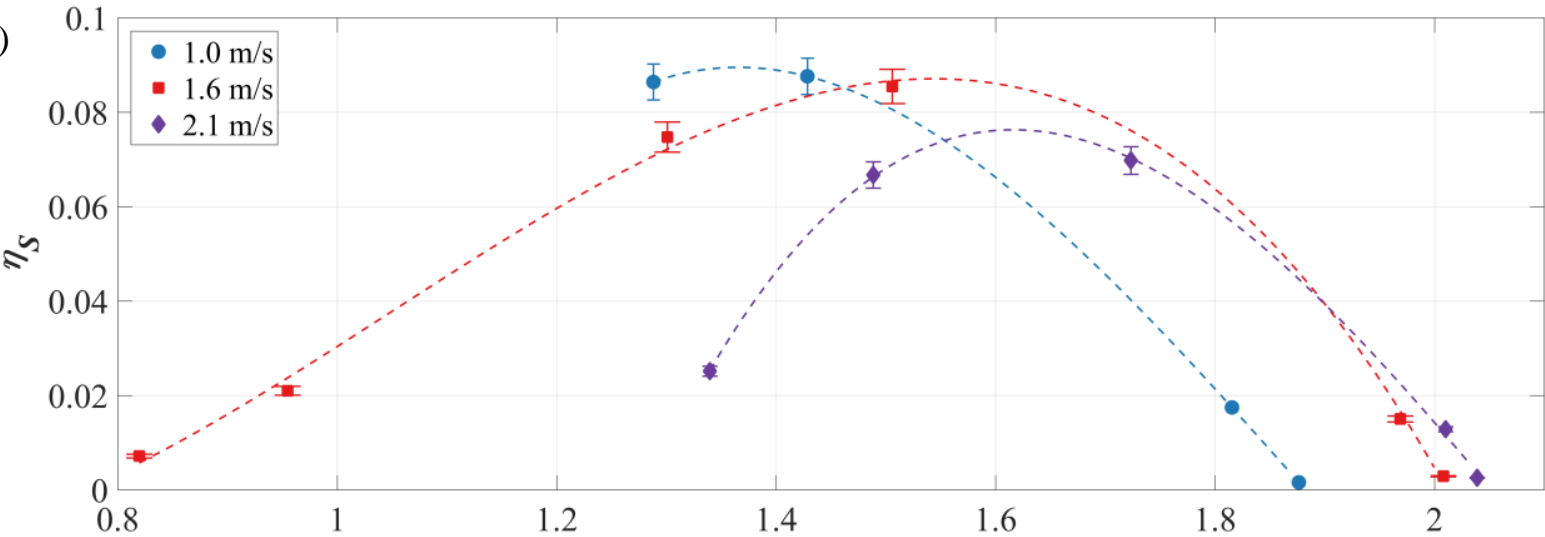

(b)
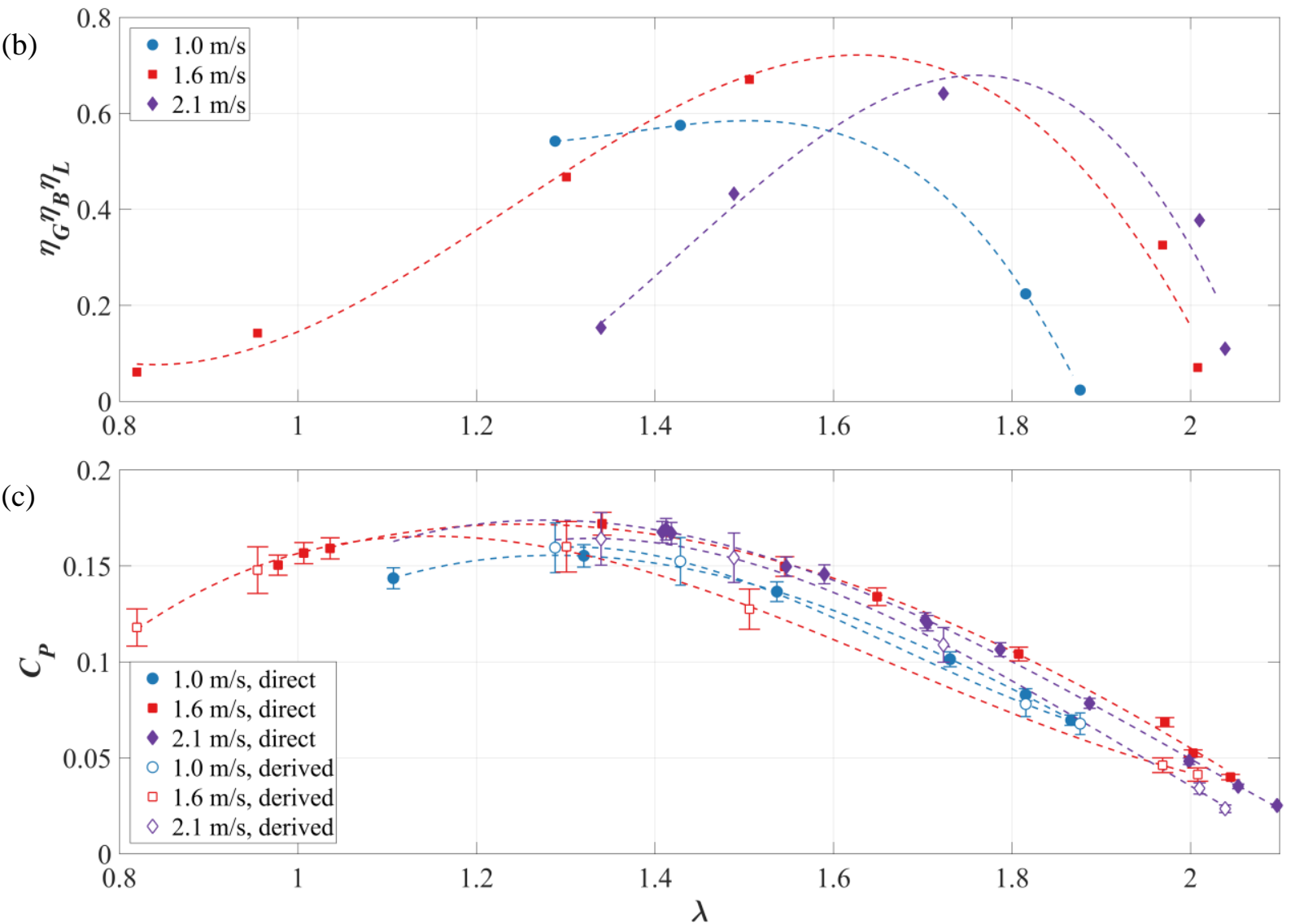

Fig. 5. System efficiency (a), PTO efficiency (b), and rotor mechanical efficiency (c).

Table 2: Peak performance results from measurements and cubic polynomial fits

\begin{tabular}{|c|c|c|c|c|c|c|c|c|c|c|c|c|c|c|c|}
\hline & \multicolumn{6}{|c|}{ Measurement } & \multicolumn{9}{|c|}{ Polynomial Fit } \\
\hline & \multicolumn{3}{|c|}{ Peak Value } & \multicolumn{3}{|c|}{ Associated $\lambda$} & \multicolumn{3}{|c|}{ Peak Value } & \multicolumn{3}{|c|}{ Associated $\lambda$} & \multicolumn{3}{|c|}{$\overline{\mathbf{R}^{2}}$} \\
\hline & $\begin{array}{l}1.0 \\
\mathrm{~m} / \mathrm{s}\end{array}$ & $\begin{array}{l}1.6 \\
\mathrm{~m} / \mathrm{s}\end{array}$ & $\begin{array}{l}2.1 \\
\mathrm{~m} / \mathrm{s}\end{array}$ & $\begin{array}{l}1.0 \\
\mathrm{~m} / \mathrm{s}\end{array}$ & $\begin{array}{l}1.6 \\
\mathrm{~m} / \mathrm{s}\end{array}$ & $\begin{array}{l}2.1 \\
\mathrm{~m} / \mathrm{s}\end{array}$ & $\begin{array}{l}1.0 \\
\mathrm{~m} / \mathrm{s}\end{array}$ & $\begin{array}{l}1.6 \\
\mathrm{~m} / \mathrm{s}\end{array}$ & $\begin{array}{l}2.1 \\
\mathrm{~m} / \mathrm{s}\end{array}$ & $\begin{array}{l}1.0 \\
\mathrm{~m} / \mathrm{s}\end{array}$ & $\begin{array}{c}1.6 \\
\mathrm{~m} / \mathrm{s}\end{array}$ & $\begin{array}{l}2.1 \\
\mathrm{~m} / \mathrm{s}\end{array}$ & $\begin{array}{l}1.0 \\
\mathrm{~m} / \mathrm{s}\end{array}$ & $\begin{array}{l}1.6 \\
\mathrm{~m} / \mathrm{s}\end{array}$ & $\begin{array}{l}2.1 \\
\mathrm{~m} / \mathrm{s}\end{array}$ \\
\hline$\eta_{S}$ & 0.088 & 0.086 & 0.070 & 1.43 & 1.50 & 1.72 & 0.090 & 0.087 & 0.076 & 1.34 & 1.54 & 1.62 & 1.00 & 1.00 & 1.00 \\
\hline$\eta_{G} \eta_{B} \eta_{L}$ & 0.575 & 0.670 & 0.641 & 1.43 & 1.50 & 1.72 & 0.585 & 0.722 & 0.679 & 1.51 & 1.63 & 1.76 & 1.00 & 0.97 & 0.92 \\
\hline$C_{P}$ (Direct) & 0.155 & 0.172 & 0.169 & 1.32 & 1.34 & 1.41 & 0.156 & 0.172 & 0.174 & 1.29 & 1.25 & 1.28 & 1.00 & 1.00 & 1.00 \\
\hline$C_{P}$ (Derived) & 0.160 & 0.160 & 0.164 & 1.29 & 1.30 & 1.34 & 0.160 & 0.165 & 0.164 & 1.31 & 1.15 & 1.33 & 1.00 & 1.00 & 1.00 \\
\hline $\begin{array}{l}\% \text { Diff. of } \\
\text { Direct and } \\
\text { Derived } C_{P}\end{array}$ & -3.2 & 7.0 & 3.0 & 2.3 & 3.0 & 5.0 & -2.6 & 4.0 & 5.7 & -1.6 & 8.0 & -3.9 & & & \\
\hline
\end{tabular}


(a)

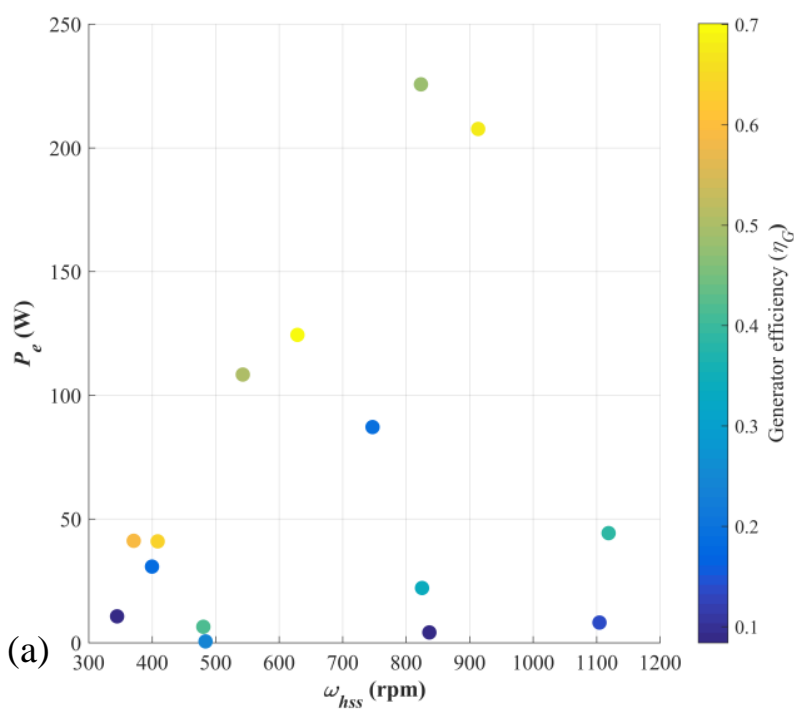

\subsection{PTO component performance}

The generator and balance of system (primarily gearbox) efficiencies depend on the combination of load and rotation rate of each steady-state test case. The generator efficiency (Fig. 6a), determined through dynamometry and the application of (10), utilized the electrical output measurements from the generator at known mechanical power points. The results indicate generally poor performance at low power outputs $(<45 \mathrm{~W})$ regardless of rotational speed. $\eta_{G}$ ranged from a minimum of $8 \%$ to a maximum of $70 \%$. Balance of system performance (Fig. 6b) was higher and less variable under the same conditions, with the exception of test points at low power and rotational speed, where the turbine was likely stalling. Excluding these outlying cases, $\eta_{B} \eta_{L}$ ranged from $66 \%$ to $98 \%$, with no clear trend in performance.

Fig. 6. Generator (a) and balance of system efficiency (b).

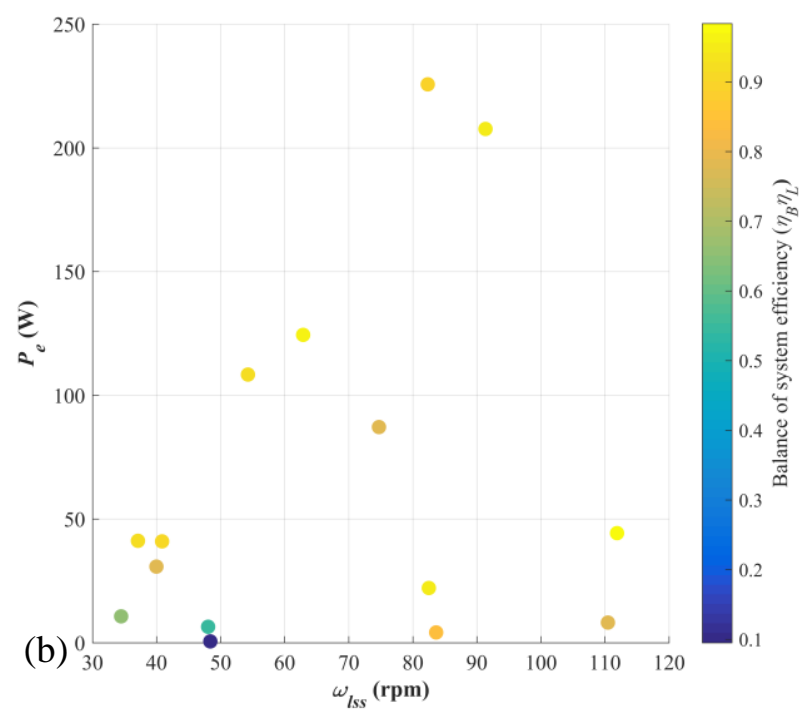

\section{Discussion}

A non-dimensional performance curve distills a turbine's hydrodynamic characteristics into a concise functional dependency on its tip-speed ratio as long as the turbine is operating at sufficiently high Reynolds number. Determination of a $C_{P-} \lambda$ curve, with an estimate of uncertainty, is an essential step in turbine development and serves as a starting point for advanced control strategies. For example, a variable-speed controller tracking a maximum power point requires accurate knowledge of a turbine's optimal operating conditions [20]. The methods and results of this study provide an accessible example of a field-scale turbine tested in open-water conditions with a complete PTO. Such results are not welldescribed in the literature.

The lake used for this testing provides lower turbulence than in a tidal channel and eliminates flow confinement effects common in a laboratory. Inhomogeneity in the inflow associated with small waves from wakes can be mitigated by sampling for much longer than the dominant period of the disturbances. An ADV was used to measure inflow conditions at the centerline of the turbine, which is likely representative of flow across the rotor in a quiescent lake. While a current profiler could be used to measure vertical variation along the blade span, this would come at the cost of reduced temporal resolution and higher uncertainty. The ADV provided the resolution to better characterize turbulent flow 
interaction with the turbine. Future studies utilizing this method may consider also deploying profiling instruments as part of the test.

The helical cross-flow turbine's peak $C_{P}$ of 0.17 at $\lambda$ of 1.3 is $50 \%$ lower than previously reported results for a helical turbine at a similar scale tested in a tow tank [21]. Several factors may account for the difference. First, the higher solidity ( 0.3 vs. 0.14$)$ of the present study's turbine favors an ability to selfstart at low speed $(0.5 \mathrm{~m} / \mathrm{s})$ at the cost of efficiency. Second, the turbine is tested in the absence of blockage, which would augment turbine efficiency. Bachant \& Wosnik's [21] experiments were conducted at a blockage of $15 \%$. This would be expected to modestly enhance efficiency, but the effect is difficult to quantify, given that commonly-used blockage corrections have been shown to be unreliable for a $1 / 4$-scale model of the presently studied turbine [10]. Similar to the present study, Shiono et al. [11] report a $C_{P}$ range of $0.20-0.23$ for a high blockage cross-flow turbine in a flume. Additionally, Kirke [22] describes a peak $C_{P}$ of 0.25 for a similarly scaled cross-flow turbine with roughly half the solidity of the presently studied design.

The consistency of the non-dimensional turbine performance at inflow speeds of $1.6 \mathrm{~m} / \mathrm{s}$ and $2.1 \mathrm{~m} / \mathrm{s}$ (Reynolds numbers of 2.4 and $3.3 \times 10^{5}$ ) suggests that these conditions exceed the critical Reynolds number. The turbine performs with a slightly lower efficiency at the lowest Reynolds number tested $\left(1.5 \times 10^{5}\right)$. This discrepancy could either result from a Reynolds independence threshold between 1.5 and $2.4 \times 10^{5}$ or the turbine experiencing higher relative frictional losses when operating at lower rotation rates.

PTO component performance is shown to substantially influence both the total system efficiency and the tip-speed ratio associated with peak efficiency. Dependence of $\eta_{G}$ on both rotation rate and power output results in $\eta_{S}-\lambda$ curves that are inflow dependent. Indeed, the poor performance of the generator highlights the importance of properly selecting or designing a generator with an operating range compatible to that of the rotor. This can be challenging for prototype field tests given the limited number of low-cost generators designed to operate at relatively low rotation rates and the limited documentation for such systems. Gearbox and balance of system efficiencies also exhibit a dynamic range, but have a less substantial influence on overall performance. In general, the authors recommend performance testing with a complete PTO system since system efficiency is of critical importance in evaluating technology readiness. However, these field tests demonstrate that PTO component efficiencies must be wellcharacterized to interpret total system performance.

A method of dynamometry that includes electromechanical emulation of the turbine is used to determine individual PTO component efficiencies. Only a small subset of possible field and lab measurements is required to accurately produce a $C_{P^{-}} \lambda$ curve from field trials. By utilizing a discrete and repeatable loading scheme in both the field and laboratory, $U_{\infty}$ and $\omega_{l s s}$ become the only necessary field measurements, while $\tilde{\tau}_{h s s}$ and $\widetilde{\omega}_{h s s}$ are the only necessary dynamometry measurements. This is because, with steady loading, a turbine's operating state is fully defined by its rotation rate. This allows field measurements of $\tau_{l s s}$, which can be difficult to obtain, to be replaced by an equivalent torque commanded for and produced by a motor in a laboratory setting. Accuracy of the derived performance curve is confirmed through comparison with a curve produced from direct measurement of the turbine's mechanical power. This method has the potential to reduce the complexity and cost of field studies for prototype hydrokinetic turbines.

\section{Conclusions}

The performance curve, PTO efficiency, and individual component efficiencies of a fullyinstrumented hydrokinetic turbine are determined through a combination of field and laboratory experiments. Tow testing through a quiescent lake is shown to be an effective method for performance 
1 characterization, providing unconfined, low turbulence conditions. The relatively poor prototype system performance is attributed to the high-solidity rotor (low peak $C_{P}$ ) and generator (low, variable $\eta_{G}$ ).

A PTO testing method is presented that allows simultaneous determination of generator and balance of system efficiencies at the same operating points as those realized during field testing. This method emulates the steady-state behavior of the turbine and can be utilized to reduce the number of necessary measurements in the field. The generator is shown to be a poor match for the turbine, while the gearbox and balance of system losses were found to be less significant. Low and highly varying generator efficiency is shown to have a strong impact on total system efficiency, leading to a strong variation in system performance with inflow velocity, even once the rotor achieves Reynolds number independence.

\section{Acknowledgements}

The authors thank current and former members of NNMREC who contributed to this work, including Adam Niblick, Nick Stelzenmuller, and Bronwyn Hughes. Thanks are also due to APL captain Andy Reay-Ellers for superb piloting, and Dr. Roy Martin for his generous support. Additional financial support was provided by the University of Washington Royalty Research Fund and US Department of Energy under DE-FG36-08GO18179.

\section{References}

[1] Sanchez, R; Technology Readiness Assessment Guide, DOE G 413.3-4A, US Department of Energy, 2011.

[2] Weber, J., Costello, R., \& Ringwood, J. (2013). WEC Technology Performance Levels (TPLs) Metric for Successful Development of Economic WEC Technology. 10th European Wave and Tidal Energy Conference. 2-5 Sept. 2013, Alborg, Denmark.

[3] Consul, C. a, Willden, R. H. J., \& McIntosh, S. C. (2013). Blockage effects on the hydrodynamic performance of a marine cross-flow turbine. Philosophical Transactions. Series A, Mathematical, Physical, and Engineering Sciences, 371, 20120299. doi:10.1098/rsta.2012.0299

[4] Polagye, B., R. Cavagnaro, and A. Niblick (2013) Micropower from Tidal Turbines, ASME Fluids Division Summer Meeting, July 8-11, 2013, Incline Village, NV.

[5] Bachant, P., \& Wosnik, M. (2014). Reynolds Number Dependence of Cross-Flow Turbine Performance and Near-Wake Characteristics. In Proc. of the 2nd Marine Energy. Seattle, WA. Retrieved from http://www.globalmarinerenewable.com/images/pdf/METS_PAPERS_VII/89Bachant.pdf

[6] Gaurier, B., Germain, G., Facq, J. V., Johnstone, C. M., Grant, A. D., Day, a. H., ... Costanzo, M. (2015). Tidal Energy "Round Robin" Tests Comparisons between towing tank and circulating tank results. International Journal of Marine Energy, 12(2015), 87-109. doi:10.1016/j.ijome.2015.05.005

[7] McCroskey, W. J. (1981). The phenomenon of dynamic stall (No. NASA-A-8464). National Aeronautics and Space Administration, Moffett Field CA, Ames Research Center.

[8] R. Alcorn \& D. O’Sullivan, Electrical Design for Ocean Wave and Tidal Energy Systems, Stevenage: The Institution of Engineering and Technology, 2014, p.2.

[9] Roos, F., Johansson, H., \& Wikander, J. (2006). Optimal selection of motor and gearhead in mechatronic applications. Mechatronics, 16(1), 63-72. doi:10.1016/j.mechatronics.2005.08.001

[10] Cavagnaro, R., Polagye, B. (2014) An evaluation of blockage corrections for a helical cross-flow turbine. In Proceedings of the $3^{\text {rd }}$ Oxford Tidal Energy Workshop, OTEW14, 7-8 April 2014, Oxford, UK 
[11] Shiono, M., Suzuki, K., \& Kiho, S. (2000). An experimental study of the characteristics of a Darrieus turbine for tidal power generation. Electrical Engineering in Japan, 132(3), 38-47. doi:10.1002/1520-6416(200008)132:3<38::AID-EEJ6>3.0.CO;2-E

[12] Paraschivoiu, I., 2002. Wind Turbine Design with Emphasis on Darrieus Concept, 1st ed., Polytechnic International, Montreal, Quebec, Canada.

[13] Chamorro, L. P., Hill, C., Neary, V. S., Gunawan, B., Arndt, R. E. A., Sotiropoulos, F. (2015). Effects of energetic coherent motions on the power and wake of an axial-flow turbine. Physics of Fluids, 27, 055104. DOI:http://dx.doi.org/10.1063/1.4921264

[14] Mori, N., T. Suzuki and S. Kakuno (2007) Noise of acoustic Doppler velocimeter data in bubbly flow, Journal of Engineering Mechanics, American Society of Civil Engineers, Vol.133, Issue 1, pp.122- 125. (doi:10.1061/(ASCE)0733- 9399(2007)133:1(122))

[15] Emery, W., Thomson, R. (2001) Chapter 5 - Time-series Analysis Methods, In Data Analysis Methods in Physical Oceanography, Elsevier Science, Amsterdam, Pages 371-567, ISBN 9780444507563, http://dx.doi.org/10.1016/B978-044450756-3/50006-X.

[16] Thomson, J., Kilcher, L., Richmond, M., Talbert, J., DeKlerk, A., Polagye, B., Cienfuegos, R. (2013). Tidal turbulence spectra from a compliant mooring. In Proceedings of the 1st Marine Energy Technology Symposium, METS 2013 (pp. 1-9). Washington, D.C.

[17] Thomson, J., Polagye, B., Durgesh, V., \& Richmond, M. C. (2012). Measurements of Turbulence at Two Tidal Energy Sites in Puget Sound, WA. IEEE Journal of Oceanic Engineering, 37(3), 363-374. doi:10.1109/JOE.2012.2191656

[18] Henriques, T., Hedges, T., Owen, I., Poole, R. (2015). The Effect of Wave-Current Interaction on the Near-Wake of Horizontal Axis Tidal Stream Turbines. Proceedings of the 11th European Wave and Tidal Energy Conference. 6-11 Sept. 2015, Nantes, France

[19] Luznik, L., Flack, K., Lust, E., Taylor, K. (2013). The effect of surface waves on the performance characteristics of a model tidal turbine. Renewable Energy, 58, 108-114. doi:10.1016/j.renene.2013.02.022

[20] Cavagnaro, R., B. Fabien, and B. Polagye (2014) Control of a helical cross-flow current turbine, Proceedings of the 2nd Marine Energy Technology Symposium, Global Marine Renewable Energy Conference, Seattle, WA, April 15-17.

[21] Bachant, P., \& Wosnik, M. (2015). Performance measurements of cylindrical- and spherical-helical cross- flow marine hydrokinetic turbines, with estimates of exergy efficiency. Renewable Energy, 74, 318-325. doi:10.1016/j.renene.2014.07.049

[22] Kirke, B. K. (2011). Tests on ducted and bare helical and straight blade Darrieus hydrokinetic turbines. Renewable Energy, 36(11), 3013-3022. doi:10.1016/j.renene.2011.03.036

[23] ASME (2005) PTC 19.1-2005 Test Uncertainty, ISBN 0791830101, American Society of Mechanical Engineers

\section{Appendix: Experimental Uncertainty}

\section{A.1 Instrumentation uncertainty}

In the following tables, systematic uncertainty for each of the sensors used for field and dynamometry testing is compiled based on manufacturers' specifications and sensor calibrations. A description of the nature and probable cause of random errors is also presented. 
Table A.1: Tow testing instrument uncertainty

\begin{tabular}{l|l|l|l|l}
\multicolumn{1}{c|}{ Instrument } & \multicolumn{1}{|c|}{$\begin{array}{c}\text { Measured } \\
\text { Quantity }\end{array}$} & \multicolumn{1}{|c|}{ Units } & \multicolumn{1}{c|}{ Systematic Uncertainty } & \multicolumn{1}{c}{ Random Uncertainty } \\
\hline Nortek Vector ADV & $\begin{array}{l}\text { Inflow water } \\
\text { velocity }\end{array}$ & $\mathrm{m} / \mathrm{s}$ & $\begin{array}{l}\text { Sensor accuracy: }+/-0.5 \% \text { of measured value }+/- \\
1 \mathrm{~mm} / \mathrm{s}\end{array}$ & $\begin{array}{l}\text { Uniformly distributed } \\
\text { Doppler noise, normally } \\
\text { distributed variation in } \\
\text { tow speed }\end{array}$ \\
\hline $\begin{array}{l}\text { RLS RM22 } \\
\text { magnetic encoder }\end{array}$ & $\begin{array}{l}\text { Rotor angular } \\
\text { position }\end{array}$ & radians & Sensor accuracy: +/- 0.012 & $\begin{array}{l}\text { Normally distributed } \\
\text { variation in rotation rate }\end{array}$ \\
\hline $\begin{array}{l}\text { LEM LA 55-P } \\
\text { current transducer }\end{array}$ & $\begin{array}{l}\text { Generator electrical } \\
\text { current }\end{array}$ & Amperes & Sensor accuracy: +/-0.9\% of measured value & $\begin{array}{l}\text { White electrical noise, } \\
\text { normally distributed } \\
\text { variation in current }\end{array}$ \\
\hline $\begin{array}{l}\text { LEM LV 25-P } \\
\text { voltage transducer }\end{array}$ & Generator voltage & Volts & Sensor accuracy: +/-0.9\% of measured value & $\begin{array}{l}\text { White electrical noise, } \\
\text { normally distributed } \\
\text { variation in voltage }\end{array}$ \\
\hline $\begin{array}{l}\text { FUTEK TRS605 } \\
\text { shaft rotary torque } \\
\text { sensor }\end{array}$ & $\begin{array}{l}\text { Hydrodynamic } \\
\text { torque }\end{array}$ & Nm & $\begin{array}{l}\text { Sensor nonlinearity: +/- 0.2\% of rated output } \\
\text { Sensor hysteresis: }+/-0.1 \% \text { of rated output } \\
\text { Sensor nonrepeatability: }+/-0.2 \% \text { or rated output } \\
\text { Summed as root sum of square, rated output of 5 } \\
\text { V at 100 Nm yields }+/-0.03 \text { Nm }\end{array}$ & $\begin{array}{l}\text { Normally distributed } \\
\text { variation in torque }\end{array}$ \\
\hline
\end{tabular}

Table A.2: Dynamometry testing instrument uncertainty

\begin{tabular}{|c|c|c|c|c|}
\hline Instrument & Measured Quantity & Units & Systematic Uncertainty & Random Uncertainty \\
\hline $\begin{array}{l}\text { Encoder Products } \\
\text { model } 260 \text { optical } \\
\text { encoder }\end{array}$ & $\begin{array}{l}\text { Generator angular } \\
\text { position }\end{array}$ & radians & Sensor accuracy: $+/-0.00017$ & $\begin{array}{l}\text { Normally distributed } \\
\text { variation in rotation rate }\end{array}$ \\
\hline $\begin{array}{l}\text { LEM LV 25-P } \\
\text { voltage transducer }\end{array}$ & Generator voltage & Volts & Sensor accuracy: $+/-0.9 \%$ of measured value & $\begin{array}{l}\text { White electrical noise, } \\
\text { normally distributed } \\
\text { variation in voltage }\end{array}$ \\
\hline $\begin{array}{l}\text { Futek TFF425 } \\
\text { reaction torque } \\
\text { sensor }\end{array}$ & $\begin{array}{l}\text { Generator reaction } \\
\text { torque }\end{array}$ & $\mathrm{Nm}$ & $\begin{array}{l}\text { Calibration uncertainty: }+/-4.0 \% \text { of measured value, } \\
\text { based on calibration of torque sensor in dynamometry } \\
\text { configuration }\end{array}$ & $\begin{array}{l}\text { Normally distributed } \\
\text { variation in torque }\end{array}$ \\
\hline
\end{tabular}

\section{A.2 Uncertainty formulation}

Uncertainty is estimated for each point on the turbine performance curve ( $C_{P}$ as a function of $\lambda$ ) following the standard on test uncertainty, ASME PTC 19.1-2005 [23]. Random errors are quantified as the standard uncertainty of the sample mean, defined as

$$
s_{\bar{X}}=\sqrt{\frac{1}{N} \sum_{j=1}^{N} \frac{\left(X_{j}-\bar{X}\right)}{N-1}}(\text { A.1) }
$$

where $\bar{X}$ is the sample mean, $N$ the number of data points, $X_{j}$ each sample point. Also known as the standard deviation of the mean, this quantity is the standard deviation of the sample normalized by the root of the number of data points collected and reflects the value of increasing the sample size in reducing uncertainty.

Systematic uncertainties, defined as the constant component of error in a measurement, are estimated to the best of the experimenters' knowledge from instrument specification sheets and calibration data. Standard systematic uncertainties are denoted as $b_{\bar{X}}$. The total uncertainty for any individual test quantity is sum of the squares of the random and systematic uncertainty,

$$
u_{\bar{X}}=\sqrt{\left(b_{\bar{X}}\right)^{2}+\left(s_{\bar{X}}\right)^{2}} \text {. (A.2) }
$$

For $95 \%$ confidence levels, the uncertainty is defined for large $N$ as,

resulting in a final value of,

$$
U_{\bar{X}}=2 u_{\bar{X}}(\mathrm{~A} .3)
$$

$$
\bar{X} \pm U_{\bar{X}} \cdot(\mathrm{A} .4)
$$




.

When the desired result is the function of multiple variables,

sensitivity is defined as

$$
R=f\left(\bar{X}_{1}, \bar{X}_{2}, \ldots \bar{X}_{I}\right)(\text { A.5) }
$$

$$
\theta_{i}=\frac{\partial R}{\partial \bar{X}_{i}}(\text { A.6) }
$$

such that the absolute random standard uncertainty for a test result is

$$
s_{R}=\sum_{i}^{I}\left[\left(\theta_{i} s_{\bar{X}_{i}}\right)^{2}\right]^{1 / 2}(\mathrm{~A} .7)
$$

and likewise for the systematic uncertainty,

$$
b_{R}=\sum_{i}^{I}\left[\left(\theta_{i} b_{\bar{X}_{i}}\right)^{2}\right]^{1 / 2} \cdot(\text { A.8) }
$$

Combining the two, the total uncertainty with $95 \%$ confidence is,

$$
U_{R, 95}=2 \sqrt{\left(s_{R}\right)^{2}+\left(b_{R}\right)^{2}}(\text { A.9) }
$$

\section{A.3 Uncertainty in typical test case}

An uncertainty calculation for $C_{P}$ from (2) for a typical test $(1.5 \mathrm{~m} / \mathrm{s}$ nominal tow speed, maximum performance) is presented as a tutorial example. The turbine radius, height, and water density are assumed to have no significant uncertainty. Restated, (2) is the kinetic power efficiency of the rotor,

Sensitivities can be analytically found,

$$
C_{P}=\frac{\tau_{\text {lss }} \omega_{\text {lss }}}{\frac{1}{2} \rho A U_{\infty}^{3}} \text {. (A.10) }
$$

0

(1)

\section{A tabulation of the uncertainty is presented in the style of the ASME standard in Table A.3.}

$$
\begin{gathered}
\theta_{\tau_{1 s s}}=\frac{\partial C_{P}}{\partial \tau_{l s s}}=\frac{2 \omega_{l s s}}{\rho A u^{3}}=\frac{C_{P}}{\tau_{l s s}} \text { (A.11) } \\
\theta_{\omega_{l s s}}=\frac{\partial C_{P}}{\partial \omega_{l s s}}=\frac{2 \tau_{l s s}}{\rho A u^{3}}=\frac{C_{P}}{\omega_{l s s}}(\mathrm{~A} .12) \\
\theta_{U_{\infty}}=\frac{\partial C_{P}}{\partial U_{\infty}^{3}}=\frac{-6 \tau_{l s s} \omega_{l s s}}{\rho A u^{4}}=\frac{-3 C_{P}}{U_{\infty}} \text {. (A.13) }
\end{gathered}
$$

Table A.3: Uncertainty Calculation for $C_{P}$, nominal $1.5 \mathrm{~m} / \mathrm{s}$, maximum efficiency

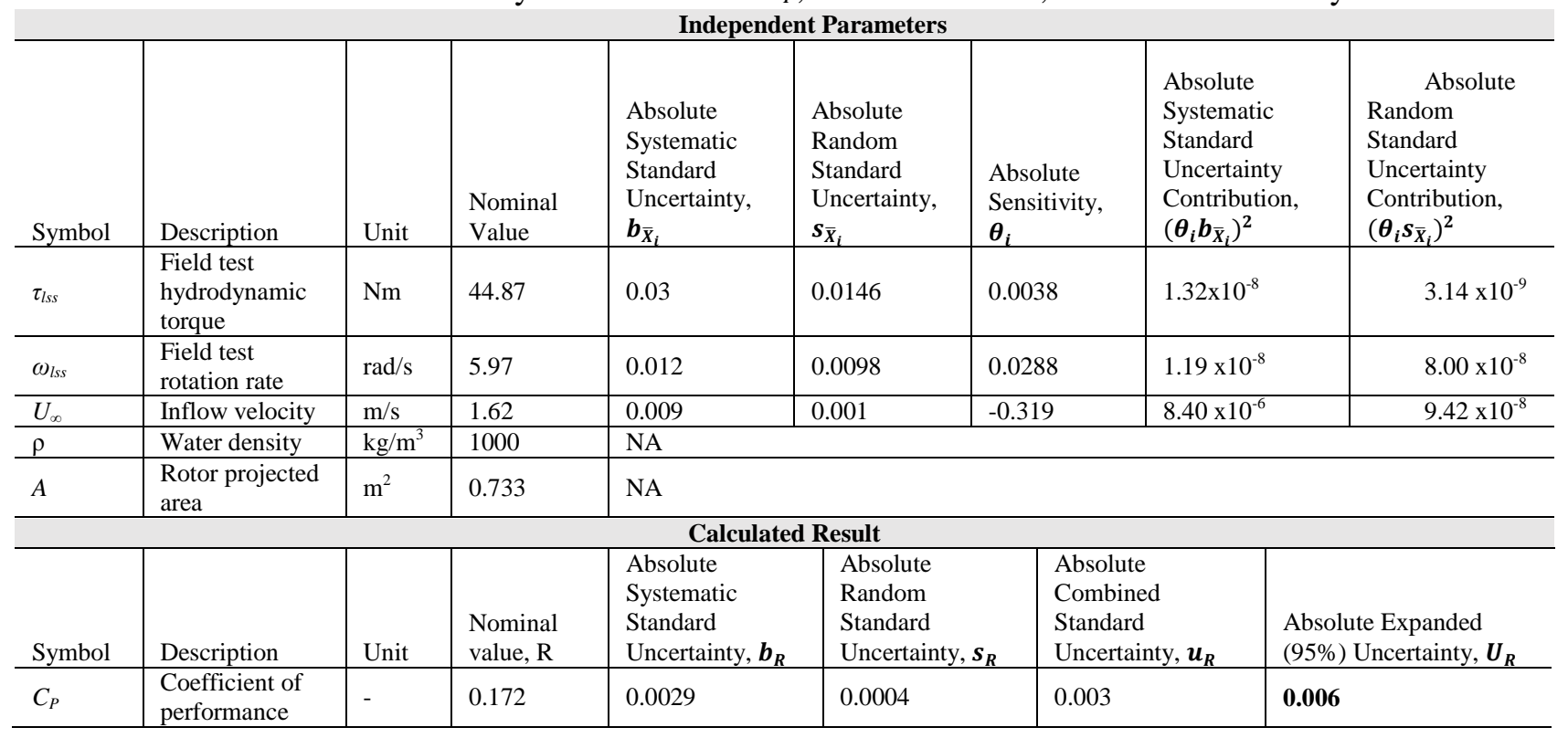


1 This analysis shows $C_{P}$ is most sensitive to changes in inflow velocity due to the cubic dependency. 2 Consequently, the velocity measurement contributes the greatest experimental uncertainty. 